\title{
Performance increase of membrane distillation pilot scale modules operating in vacuum-enhanced air-gap configuration
}

\author{
J.A. Andrés-Mañas ${ }^{\mathrm{a}}$, A. Ruiz-Aguirre ${ }^{\mathrm{b}}$, F.G. Acién ${ }^{\mathrm{a}}$, G. Zaragoza ${ }^{\mathrm{c}, *}$

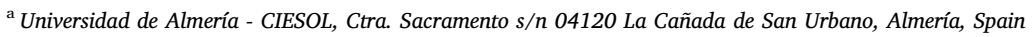 \\ ${ }^{\mathrm{b}}$ Dipartimento di Ingegneria, Università degli Studi di Palermo (UNIPA), Palermo, Italy \\ ${ }^{\mathrm{c}}$ CIEMAT - Plataforma Solar de Almería, Ctra. De Senés s/n, 04200 Tabernas, Almería, Spain
}

\section{A R T I C L E I N F O}

\section{Keywords:}

Membrane distillation

Solar desalination

Brine treatment

Vacuum-enhanced AGMD

Energy efficiency

\begin{abstract}
A B S T R A C T
This paper presents the first experimental evaluation at pilot scale of the operation of vacuum-enhanced air-gap membrane distillation (V-AGMD) using two commercial spiral-wound modules at Plataforma Solar de Almería's solar desalination test facilities. The main difference between the modules was the channel length (1.5 and $2.7 \mathrm{~m})$ as a result of having different membrane surface area $\left(7.2 \mathrm{~m}^{2}\right.$ and $25.9 \mathrm{~m}^{2}$ respectively) and different number of envelopes. Suction of air from the gap improved the vapour transfer through the membrane pores and the performance of the modules was significantly increased in relation to common air-gap (AGMD) operational mode, especially in the treatment of high salinity feeds. Increases of up to $234 \%$ in permeate flux and decreases of $68 \%$ in specific thermal energy consumption were measured. Depending on the channel length of the modules, the effect of vacuum led to extreme permeate productivity $\left(8.71 \mathrm{~h}^{-1} \mathrm{~m}^{-2}\right)$ in the shortest, or to extreme energy efficiency $\left(49 \mathrm{kWh}_{\mathrm{th}} \mathrm{m}^{-3}\right.$, equivalent to a GOR of 13.5) in the longest. These are the best experimental performances obtained so far with pilot scale modules in membrane distillation.
\end{abstract}

\section{Introduction}

One of the main barriers for the commercial implementation of membrane distillation (MD) is its high energy consumption [1,2]. Energy is hardly free, so this has a strong impact on the cost, especially regarding the application of MD to solar desalination [3]. The studies of thermal efficiency in MD must be done at pilot-scale [4-6], since labscale results cannot be extrapolated, especially those regarding energy efficiency $[7,8]$. Amongst the means for increasing the thermal energy efficiency in $\mathrm{MD}$, the recovery of latent heat of condensation as sensible heat to preheat the feed in multi-stage arrangements has been proposed. Several theoretical multi-stage MD models were developed for estimating the performance depending on the number of stages and the feed salinity $[9,10]$. Tests performed in different multi-stage units, both for hollow fibre [11] and plate and frame modules [12-14] confirmed the reduction of the energy consumption. This solution, however, increased the number of units and external devices, hence the investment costs, as well as the operational costs due to increased pumping energy for circulation.

A more optimal solution is to recover the latent heat of condensation internally, with a design that allows preheating the feed flow in the condensation channel with the latent heat released by the condensing vapour inside the module. The Fraunhofer Institute of Solar Energy developed and characterised commercial spiral wound modules with up to $14 \mathrm{~m}^{2}$ membrane area, in which this concept is applied [15]. The spiral wound geometry maximises the ratio between the contact area and the footprint, and reduces thermal losses by introducing the coldest current near the wall of the module. Then, the German company SolarSpring $\mathrm{GmbH}$ developed demonstration plants with spiral wound modules in permeate-gap configuration (PGMD) that were placed in offgrid rural settlements for the autonomous decentralized production of potable water, with no need of qualified work staff, and using solar and waste heat as thermal source. In these systems, permeate productions were up to $2.11 \mathrm{~h}^{-1} \mathrm{~m}^{-2}$ with minimum specific thermal energy consumption (STEC) of $170 \mathrm{kWh}_{\mathrm{th}} \mathrm{m}^{-3}$ [16,17]. A full characterization of the module with $10 \mathrm{~m}^{2}$ membrane surface area for seawater desalination showed minimum STEC of $224 \mathrm{kWh}_{\mathrm{th}} \mathrm{m}^{-3}$ (operating at $80^{\circ} \mathrm{C}$ feed temperature, $20^{\circ} \mathrm{C}$ cooling temperature and $4001 \mathrm{~h}^{-1}$ feed flow rate) and permeate flux of $2.71 \mathrm{~h}^{-1} \mathrm{~m}^{-2}$ (operating at the same temperatures but $600 \mathrm{lh}^{-1}$ feed flow rate) [18].

A similar heat recovery concept is pursued by the Dutch company Aquastill BV, who fabricates advanced spiral-wound air-gap membrane distillation (AGMD) modules. Their novelty is that they use several rolled envelopes forming a number of internal evaporation and cooling

\footnotetext{
* Corresponding author.

E-mail address: guillermo.zaragoza@psa.es (G. Zaragoza).
} 
channels, which facilitates the use of larger membrane areas in a single module for improving the thermal efficiency $[19,20]$. Some studies have been carried out with Aquastill modules with membrane surface areas of 7.2 and $24 \mathrm{~m}^{2}$. A real application of a pilot MD system bearing one of the $7.2 \mathrm{~m}^{2}$ modules for the desalination of groundwater from a coal seam gas mine was evaluated by Duong et al. [21], operating in a hybrid RO-MD facility. The concentration of the RO brine by MD yielded $1.41 \mathrm{~h}^{-1} \mathrm{~m}^{-2}$ permeate flux, with specific thermal consumption around $200 \mathrm{kWh}_{\mathrm{th}} \mathrm{m}^{-3}$. A theoretical model of DCMD was adapted to AGMD and validated experimentally by Hitsov et al. [22] with data from modules of 7.2 and $24 \mathrm{~m}^{2}$ membrane surface areas for different operating conditions and feed concentrations up to $200 \mathrm{gl}^{-1}$. The feasibility of the $7.2 \mathrm{~m}^{2}$ AGMD module for the desalination of seawater was assessed in long-term experiments, reporting values of specific thermal energy consumption as low as $90 \mathrm{kWh}_{\mathrm{th}} \mathrm{m}^{-3}$ with simulated seawater as saline source (operating at $70^{\circ} \mathrm{C}$ feed temperature, $25{ }^{\circ} \mathrm{C}$ cooling temperature and $1501 \mathrm{~h}^{-1}$ feed flow rate) [23]. These are almost half the best value obtained in some other studies with spiral wound and plate and frame modules [24]. Ruiz-Aguirre et al. [25] carried out later a characterization and optimization of the aforementioned AGMD modules for seawater desalination, taking into account the operating conditions and the internal design of the module. The length of the internal channels was identified as the most critical parameter to be considered when looking for the optimal trade-off between productivity and energy efficiency in an MD pilot plant, due to its influence on the residence time. Minimum thermal consumption close to $100 \mathrm{kWh}_{\mathrm{th}} \mathrm{m}^{-3}$ was reported for the $24 \mathrm{~m}^{2}$ module (operating at $80^{\circ} \mathrm{C}$ feed temperature, $25^{\circ} \mathrm{C}$ cooling temperature and $5001 \mathrm{~h}^{-1}$ feed flow rate), and maximum permeate flux of $4.31 \mathrm{~h}^{-1} \mathrm{~m}^{-2}$ was obtained with the $7.2 \mathrm{~m}^{2}$ one (operating at $80^{\circ} \mathrm{C}$ feed temperature, $20^{\circ} \mathrm{C}$ cooling temperature and $600 \mathrm{lh}^{-1}$ feed flow rate).

Internal heat recovery has been tried in hollow-fibre modules [26-28], but always at a reduced scale, with maximum membrane surface area of $2 \mathrm{~m}^{2}$ [29]. For modules with membrane surface areas equivalent to the spiral-wound modules discussed before, heat must be recovered externally with the consequent increase of investment costs and electrical consumption.

Another way to improve the thermal efficiency of MD is by increasing the permeate production for the same energy input. Since the early development of AGMD modules, some laboratory studies demonstrated that the removal of air from the membrane pores reduces drastically the mass transfer resistance that hinders the permeate production [30-32]. An increase of the performance was observed working with pilot-scale spiral wound modules when air was removed from the feed solution before entering the module [33]. This can be achieved using vacuum as a way of removing non-condensable gases from the gap and the membrane pores in AGMD configuration. This vacuumenhanced air-gap configuration (V-AGMD) is different from vacuum membrane distillation (VMD). In the latter, absolute pressure inside the module is low enough for modifying the liquid-vapour equilibrium, and vapour is condensed outside it. In V-AGMD, the vacuum is weaker and higher than the equilibrium pressure, so the vapour is condensed inside the gap. Vacuum's role is thus merely to suck air from the gap and decrease the mass transfer resistance.

Early studies demonstrated also major flux and thermal efficiency improvements both in flat plate [34] and hollow-fibre units [35,36], but associated to a higher total energy consumption as a consequence of using a vacuum pump. Winter [37] used sodium chloride solutions with concentrations up to $220 \mathrm{~g} \mathrm{l}^{-1}$ in his study of several MD configurations in a bench-scale facility that included an AGMD arrangement in which vacuum could be applied. The highest permeate flux $\left(2.61 \mathrm{~h}^{-1} \mathrm{~m}^{-2}\right)$ and the lowest specific energy consumption $\left(127 \mathrm{kWh}_{\mathrm{th}} \mathrm{m}^{-3}\right)$ were obtained with V-AGMD (i.e., the permeate flux increased 1.25-2.5 times and the specific energy consumption was 2-2.5 times lower in relation to AGMD).

As mentioned before, the main drawback for the implementation of
V-AGMD configuration is the additional energy consumption to generate the vacuum. In this sense, the company Aquastill BV has devised a system with minimum additional electrical consumption, because of the absence of a vacuum pump. The results reported in this paper are the first obtained outdoors for V-AGMD configuration with commercial modules at pilot scale. Experiments were performed at the solar membrane distillation pilot facilities of Plataforma Solar de Almería (SE Spain), using a novel Aquastill system able to operate in AGMD and VAGMD modes, with modules of 7.2 and $25.9 \mathrm{~m}^{2}$. Thus, this study provides more useful information in terms of energy efficiency and permeate production than the experiments obtained at lab-scale, with regard to a potential upscaling of MD.

\section{Materials and methods}

\subsection{Description of the pilot system}

The pilot MD system assessed in this work is a commercial unit developed by the Dutch company Aquastill BV, and it was operated in one of the solar MD pilot plants at Plataforma Solar de Almería (PSA). It can accommodate different MD modules with AGMD configuration. The main innovation is that the system can also be operated in V-AGMD mode besides conventional AGMD. Fig. 1 shows a graphical scheme of the system. The pilot has separate heating and cooling systems, both using centrifugal pumps and plate and frame heat exchangers. The cooling circuit has a narrowing tube connected with the permeate collection system. This way, the circulation of the cooling flow generates a Venturi effect that extracts air from the permeate channel of the module. This is indicated by the purple dashed line in Fig. 1. The narrowing tube is directly connected to the permeate collection tank, and the latter, in turn, connected to the permeate channel, i.e. the air gap. This way, most non-condensable gases in the gap are sucked to the permeate tank and are finally released to the atmosphere through the open cooling storage. The vacuum level is slightly dependent on the operating conditions, because of the different vapour production inside the module. Absolute pressure was similar for comparable operating conditions, and measured values fell typically between 150 and 200 mbar. This vacuum level is not sufficient to alter the water-vapour equilibrium in the permeate channel. Therefore, all vapour is condensed inside the gap and flows out as liquid permeate to be stored in a 5-1 vessel which is automatically discharged (controlled by the signals of two level sensors), releasing a constant amount of 3.21 per discharge. The feed flow rate and hydraulic pressure are measured at the inlet of the cooling channel, just before entering the module. The absolute pressure in the gap is measured with a pressure gauge. Finally, the four temperatures from the inlets and outlets of the module, the feed flow rate, the pressure drop, and the number of discharges from the permeate vessel are recorded by a PLC for subsequent access.

Two different AGMD modules were evaluated in this pilot plant: one of them with reference AS7C1.5L (named AS7 hereinafter), and the other with reference AS26C2.7L (named AS26 hereinafter). Both modules have spiral-wound geometry and are enclosed in a plastic insulating material coated with anti-thermal paint. The membrane is similar in both modules, made of low-density polyethylene (LDPE), with no backing, mean pore diameter $0.32 \mu \mathrm{m}$, thickness $76.0 \mu \mathrm{m}$ and porosity 76.0\%. The module AS7 has an effective membrane area of $7.2 \mathrm{~m}^{2}$, and the AS26 $25.9 \mathrm{~m}^{2}$. The former has six spiral envelopes, which delimit twelve internal circulation channels with polypropylene spacers inside them: six of them are evaporation channels (delimited by the membranes), and the other six cooling channels (delimited by $80-\mu \mathrm{m}$ thick condensation foils, made in polyethylene terephthalate (PET) coated with aluminium). Both kinds of channels are $2.0 \mathrm{~mm}$ width, have an effective height of $0.4 \mathrm{~m}$, and are $1.5 \mathrm{~m}$ long. On the other hand, the AS26 module has twelve envelopes, delimiting 24 channels $2.7 \mathrm{~m}$ long each, twelve for evaporation and twelve for cooling. Both modules are made of the same materials, and it must be emphasized 


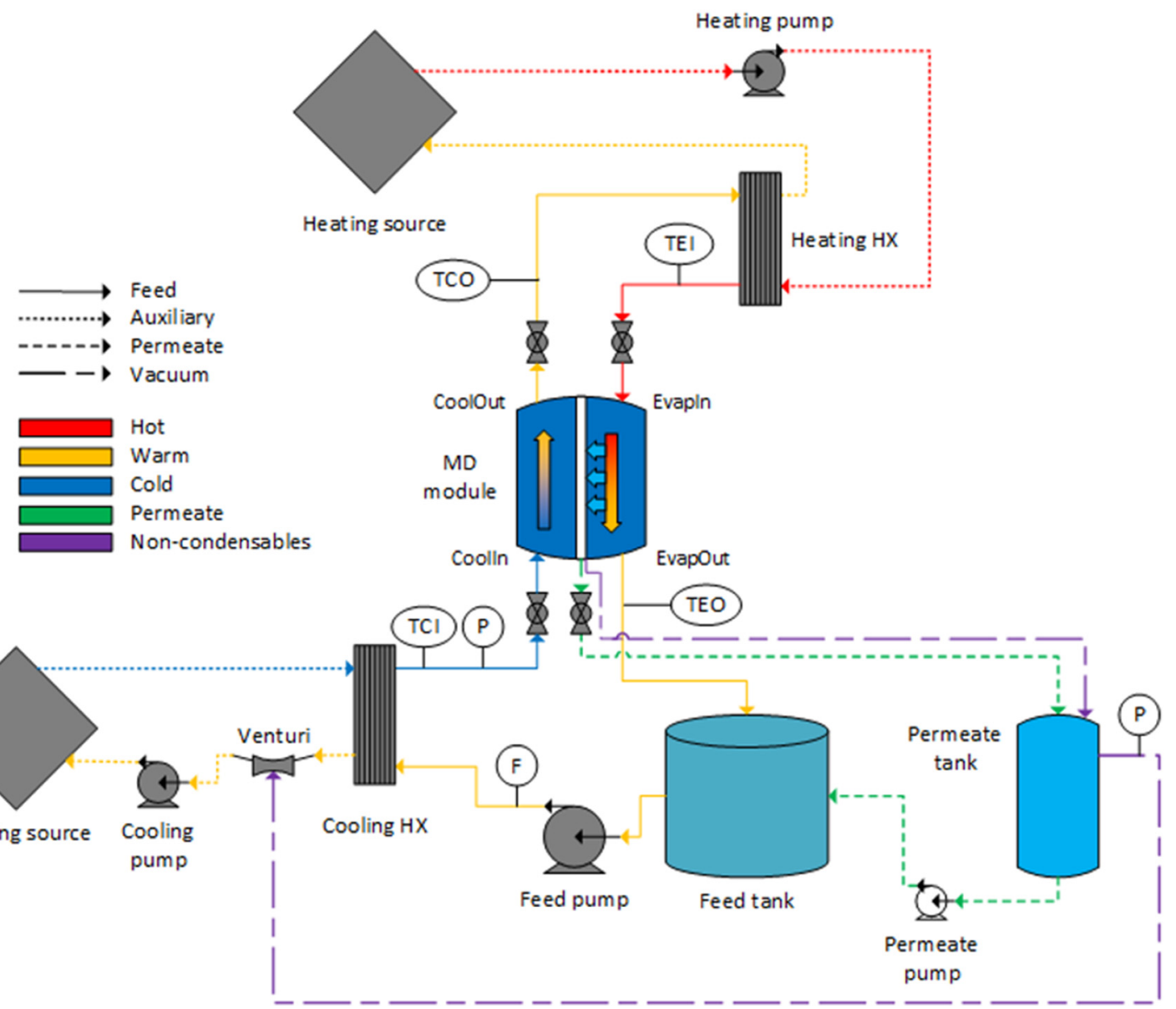

Fig. 1. Diagram showing the layout of the Aquastill system.

that the two main differences between them are the number of channels and their length, which affects the residence time. Since the flux is split in twice more channels that are 1.8 times longer, the residence time of the feed in the AS26 module is 3.6 times longer that of the AS7 for the same flow rate. Thus, the performance of the AS26 module is expected to be very different than that of the AS7 module, and more similar to that of the AS24 module with $24 \mathrm{~m}^{2}$ membrane surface area and six envelopes which has been used in other works by the authors [20,25]. With the same number of channels as the AS7 but $5 \mathrm{~m}$ long, the AS24 has 3.3 times longer residence time than the AS7, so there is only $93 \%$ difference with the AS26 module. The air gap thickness in both modules is $0.76 \mathrm{~mm}$. The modules have four hydraulic connections with Pt-100 temperature sensors outside. Two of the connections are the inlets of the cooling and evaporation channels, while the other two are the corresponding outlets (one single inlet and one single outlet for all the internal channels in each side of the membrane, distribution taking place inside the module).

Before entering the module, the feed must pass through the heat exchanger in the cooling circuit for dropping its temperature to the desired cooling channel inlet temperature (TCI). Then, it enters the cooling channels where it gains sensible heat coming both from the latent heat delivered by the condensing vapour on the foils in the gap, and from the sensible heat transferred by conduction. The feed circulating through the cooling channels flows tangentially and countercurrent with the one in the evaporation channels, i.e., the feed enters the cooling channels surrounding the wall of the module, while the evaporation channels inlet (the hottest current) is placed near its core. This hydraulic configuration provides additional thermal insulation to the module from losses through its walls. The preheated feed leaves the cooling channels at temperature TCO and passes through the heat exchanger in the heating circuit to gain the rest of sensible heat required for reaching the setpoint evaporation channels inlet temperature (TEI). The hot feed flows through the evaporation channels and vapour passes through the membrane pores because of the vapour pressure gradient between both sides of it. The vapour is condensed onto the foils that delimit the gap, as explained before, and is finally collected as permeate. The brine with temperature TEO leaves the module at the evaporation channels outlet and is collected in the feed tank. During these experiments, the discharged permeate was returned back to the feed tank. This way, the feed could be reused in a closed loop during the operation and its concentration was maintained almost constant in all the tests performed at a given salinity.

\subsection{Experimental procedure}

The experimental campaign with the pilot MD system consisted of steady-state tests performed with nominal operational conditions in both modules: inlet temperature of the evaporation channels of $80^{\circ} \mathrm{C}$, inlet temperature of the cooling channels of $25^{\circ} \mathrm{C}$, and feed flow rate of $1100 \mathrm{l} \mathrm{h}^{-1}$. A duration of 20-30 min was enough for getting the system steady before each test. Absolute pressure in the gap was around 150-200 mbar, high enough to avoid altering the liquid-vapour equilibrium and allow the vapour to condense inside the gap of the module. Several saline solutions were used in this evaluation, with concentrations between 0.6 and $5.0 \mathrm{M}$ (equivalent to 35.1 and $292.2 \mathrm{gl}^{-1}$ ), respectively, prepared by using high-purity sodium chloride tablets and demineralized water. The preparation of a large volume of feed (300l) reduced temperature and concentration changes in the feed tank during the operation. All the experiments were performed with vacuum enhancement (V-AGMD) in both modules, and then remade in common 


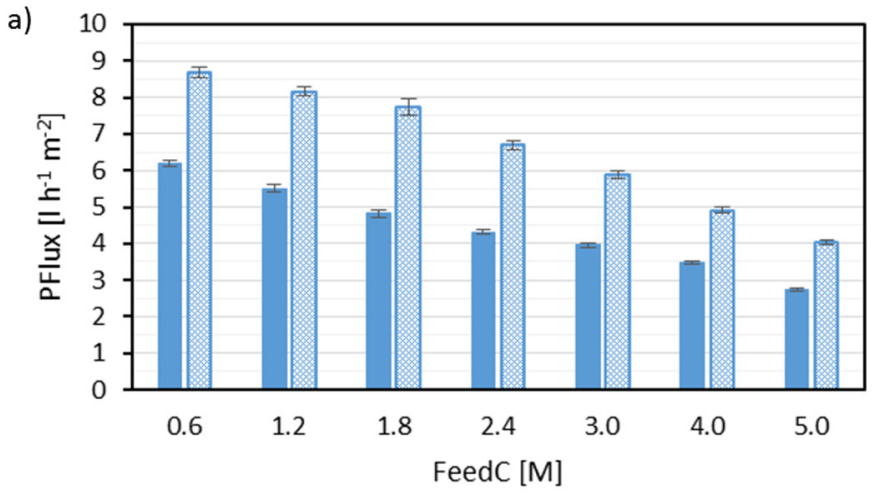

AGMD, AS7 $⿴ 囗 \mathrm{~V}-\mathrm{AGMD}, \mathrm{AS7}$

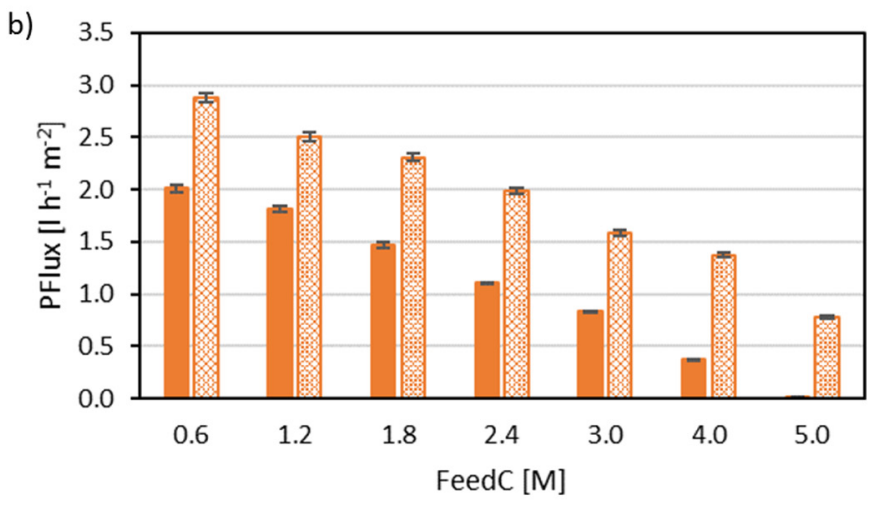

\section{AGMD, AS26}

Fig. 2. Comparative results of PFlux in experiments performed in AGMD (filled columns) and V-AGMD (striped columns) using the AS7 (a) and the AS26 (b) modules, respectively, for different feed salinities. TEI $=80^{\circ} \mathrm{C}, \mathrm{TCI}=25^{\circ} \mathrm{C}$, $\mathrm{FFR}=11001 \mathrm{~h}^{-1}$. Error bars are shown.

AGMD mode with the same operational conditions and feed salinities. The effect of vacuum was assessed considering the two main performance indicators of MD: permeate flux (PFlux) and specific thermal energy consumption (STEC). The former represents the permeate production per unit of membrane area, whereas the latter is defined as the amount of thermal energy consumed by the system per unit volume of permeate produced, and is calculated as:

$S T E C=\frac{F F R \cdot \rho_{f} \cdot C_{p f} \cdot(T E I-T C O)}{P F l u x \cdot \rho_{p} \cdot A}$

where $A$ is the membrane surface area, $\rho_{f}$ and $\rho_{p}$ are the feed and permeate density, respectively, and $C_{p f}$ is the specific heat capacity of the feed. The physical properties were estimated following the correlations in [38].

As explained before, the latent heat of condensation is recovered as sensible heat inside the module for preheating the feed. The overall thermal efficiency of the membrane $(\eta)$ is the ratio between the latent heat recovered from the condensing vapour and the total heat transferred through the membrane, and is formulated as:

$\eta=100 \cdot\left(\frac{P F l u x \cdot \rho_{p} \cdot A \cdot \Delta H_{V}}{F F R \cdot \rho_{f} \cdot C_{p f} \cdot(T C O-T C I)}\right)$

where $\Delta H_{V}$ is the latent heat of vaporization of the permeate [38].

Permeate samples were taken in different discharges of every experiment and their electrical conductivity was measured to evaluate the quality of the permeate production. For that, the salt rejection factor (SRF) was used. It indicates the amount of salts rejected from the feed by the membrane and is calculated as:

$S R F=100 \cdot\left(1-\frac{\text { Perm } C}{\text { Feed } C}\right)$

where PermC and FeedC are the concentration of the permeate and the feed, respectively, calculated from the correlation indicated in [39].

In addition, the membrane leak ratio was estimated as a measurement of how much feed passed through the membrane during the operation:

Membrane leak ratio $=100 \cdot\left(\frac{\text { PFlux } \cdot A \cdot P e r m C}{\text { FFR } \cdot \text { FeedC }}\right)$

Since the temperature of the membrane cannot be measured in pilot-scale modules, for approximating the transmembrane temperature difference the logarithmic mean of the temperature differences in the bulk of both channels was used, as typically done in pilot-scale MD modules [18,25]:

$\Delta T_{m l}=\frac{(T E I-T C O)-(T E O-T C I)}{\ln \left(\frac{T E I-T C O}{T E O-T C I}\right)}$

Similarly, the driving force of membrane distillation, which is defined as the transmembrane pressure difference between both sides of the membrane [30], was estimated in this work with the logarithmic mean of the vapour-liquid equilibrium saturation pressures corresponding to the four bulk temperatures:

$\Delta P_{v}=\frac{\left(P_{s a t_{E I}}-P_{s a t_{C O}}\right)-\left(P_{s a t_{E O}}-P_{s a t_{C I}}\right)}{\ln \left(\frac{P_{s a t_{E I}}-P_{s a t_{C O}}}{\text { Psat }_{E O}-P_{s a t_{C I}}}\right)}$

Finally, performance results in this study were compared with others reported in the literature. Previous thermal desalination studies established the gained output ratio (GOR) as the most useful energy parameter to perform a comparative benchmarking between different systems. For MD, GOR is defined as the ratio between the energy required for vaporizing the total permeate production and the energy added externally to the system [40]:

$G O R=\frac{P F l u x \cdot \rho_{p} \cdot A \cdot \Delta H_{V}}{F F R \cdot \rho_{f} \cdot C_{p f} \cdot(T E I-T C O)}$

\section{Results and discussion}

\subsection{Permeate productivity}

The permeate productivity results are given in terms of permeate flux (PFlux). Fig. 2a and b summarize the values obtained with modules AS7 and AS26 respectively in AGMD and V-AGMD operational modes for the different feed salinities considered. As expected, the permeate flux decreased with feed salinity in both modules and both operational modes AGMD and V-AGMD, because of the decrease of the vapour pressure of the feed source with salinity. Additionally, results showed that the application of vacuum in the gap increased significantly the permeate productivity for every feed salinity. PFlux values when using the AS7 module were between $8.71 \mathrm{~h}^{-1} \mathrm{~m}^{-2}$ with FeedC $=0.6 \mathrm{M}$ and $4.01 \mathrm{~h}^{-1} \mathrm{~m}^{-2}$ with FeedC $=5.0 \mathrm{M}$. In the case of the AS26 module, these values also dropped almost linearly with FeedC from $2.91 \mathrm{~h}^{-1} \mathrm{~m}^{-2}$ to $0.81 \mathrm{~h}^{-1} \mathrm{~m}^{-2}$.

Fig. 3 shows the relative improvement of PFlux in V-AGMD in relation to AGMD experiments with the same operational conditions. The relative increase of the permeate productivity in the V-AGMD mode when using the AS7 module was not very dependent on the feed salinity even at its highest values, remaining at ( $40 \pm 10) \%$ for every case. On the contrary, in the AS26 module the higher the feed concentration, the greater the productivity improvement was when using the V-AGMD mode. In AGMD operation, the AS26 module was more affected by feed 


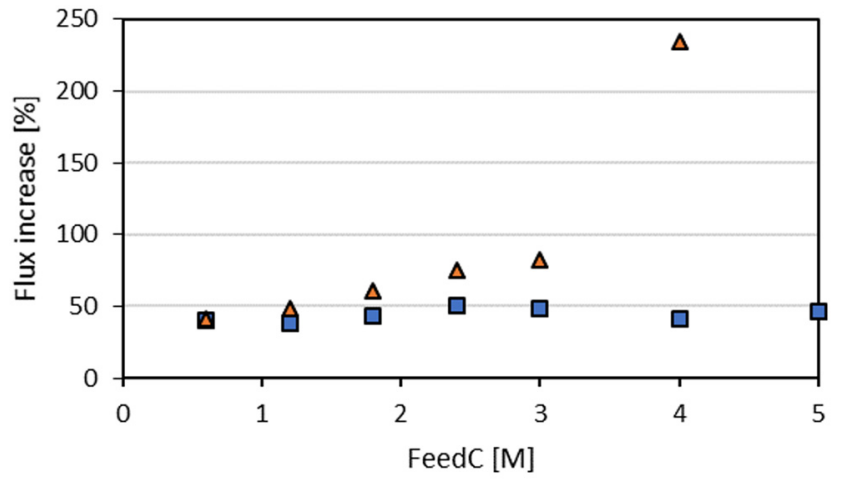

口AS7 $\triangle$ AS26

Fig. 3. Relative increases in PFlux when the vacuum enhancement is applied in the AS7 (blue squares) and the AS26 (orange squares) modules, respectively, for different feed salinities. TEI $=80^{\circ} \mathrm{C}$, TCI $=25^{\circ} \mathrm{C}, \mathrm{FFR}=1100 \mathrm{lh}^{-1}$. (For interpretation of the references to colour in this figure legend, the reader is referred to the web version of this article.)

salinity, to the point that its productivity was reduced to almost zero at FeedC $=5.0 \mathrm{M}$. This is because the decrease of the vapour pressure with the feed salinity reduced the driving force too much for an effective vapour flux to take place through the membrane. This effect is more important in modules with larger residence time (typically due to longer channels) where the driving force is smaller [25], which is here the case of the AS26 module compared to the AS7. Thus, when the VAGMD mode was used in the AS26 module the impact was more remarkable. The relative increase of productivity ramped up linearly up to a value of $82 \%$ for $3.0 \mathrm{M}$, exceeding that obtained in previous benchscale V-AGMD tests [37]. In the case of $4.0 \mathrm{M}, 235 \%$ more permeate was measured in V-AGMD mode. Finally, in the limit case of FeedC $=5.0 \mathrm{M}$, the use of V-AGMD allowed collecting a measurable amount of permeate, which was not possible in standard AGMD operation as discussed before.

\subsection{Thermal efficiency}

The thermal energy efficiency of the system, given in terms of the specific thermal energy consumption (STEC), was also calculated and compared for both AGMD and V-AGMD modes. Results for AS7 and AS26 modules are presented in Fig. 4. As a consequence of the higher permeate fluxes observed in all these comparative tests, results of STEC were also improved by the use of vacuum in both modules, in relation to the AGMD operation. In both operational modes, noticeable growth of the thermal energy needs was observed as the feed salinity increased.

The values of relative improvement of STEC when the vacuum enhancement was used are presented in Fig. 5. Little variation in the relative decrement of STEC with the feed salinity was found when working with the AS7 module, with an average decrease of $(40 \pm 6)$ $\%$. In the operation of the AS26 module, relative STEC decrease also resulted almost independent of the feed salinity up to $3.0 \mathrm{M}$, with an average decrease of $(44 \pm 7) \%$, similar to that obtained in previous $\mathrm{V}$ AGMD bench-scale tests [37]. From that concentration onwards, the thermal efficiency enhancement increased with the feed salinity, reflecting the effect referred before of the permeate production being extended to higher salinities in the V-AGMD mode.

As a result of the larger permeate flux in V-AGMD operation, the transfer of latent heat increased. This is reflected in the overall thermal efficiency of the membrane ( $\eta$ ), which also gets better by extracting the air from the gap. As shown in Fig. $6 \mathrm{a}$ for the AS7 module and Fig. $6 \mathrm{~b}$ for the AS26 module, $\eta$ increased in V-AGMD operation.

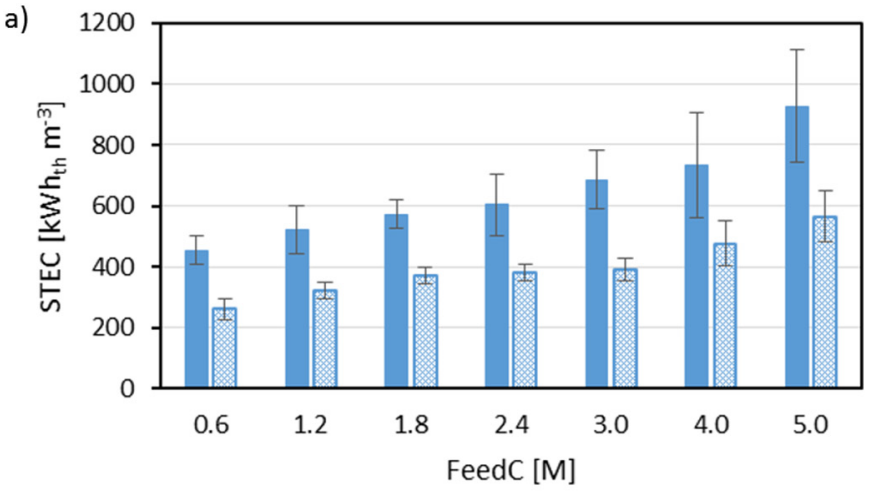

- AGMD, AS7 V-AGMD, AS7

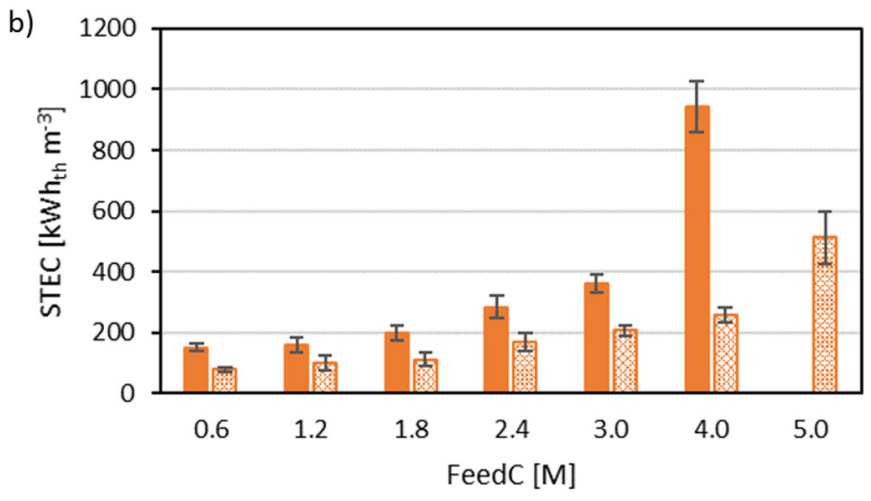

AGMD, AS26 $₫$ V-AGMD, AS26

Fig. 4. Comparative results of STEC in experiments performed in AGMD (filled columns) and V-AGMD (striped columns) using the AS7 (a) and the AS26 module (b), respectively, for different feed salinities. TEI $=80{ }^{\circ} \mathrm{C}, \mathrm{TCI}=25^{\circ} \mathrm{C}$, $\mathrm{FFR}=1100 \mathrm{~h} \mathrm{~h}^{-1}$. Error bars are shown.

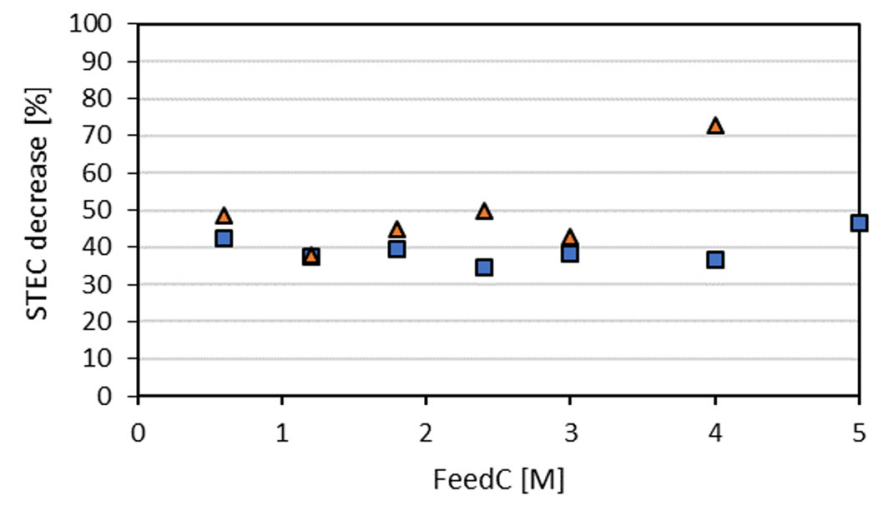

\section{$\square$ AS7 $\triangle$ AS26}

Fig. 5. Relative decreases in STEC when the vacuum enhancement is applied in AS7 (blue squares) and AS26 (orange squares) modules, respectively, for different feed salinities. TEI $=80^{\circ} \mathrm{C}$, TCI $=25^{\circ} \mathrm{C}$, FFR $=11001 \mathrm{~h}^{-1}$. (For interpretation of the references to colour in this figure legend, the reader is referred to the web version of this article.)

\subsection{Permeate quality}

Permeate quality is another parameter that must be taken into account when assessing the performance of pilot MD systems. In this work, it was analysed using the salt rejection factor (SRF), calculated with Eq. (3). Table 1 shows the values of SRF calculated for the AS7 


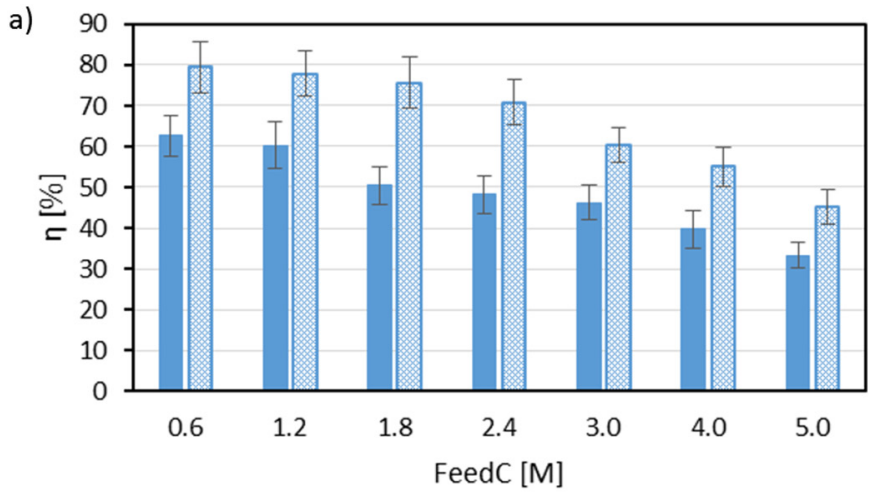

AGMD, AS7 ㅈ-AGMD, AS7

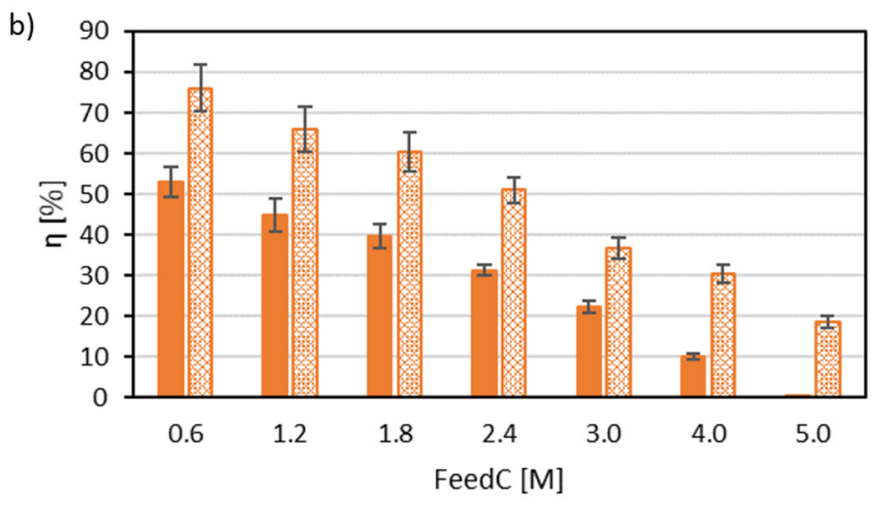

\section{AGMD, AS26 $\approx$ V-AGMD, AS26}

Fig. 6. Comparative results of $\eta$ in experiments performed in AGMD (filled columns) and V-AGMD (striped columns) using the AS7 (a) and the AS26 module (b), respectively, for different feed salinities. TEI $=80^{\circ} \mathrm{C}, \mathrm{TCI}=25^{\circ} \mathrm{C}$, $\mathrm{FFR}=11001 \mathrm{~h}^{-1}$. Error bars are shown.

module and the AS26 module, respectively. Unfortunately, for higher feed salinities it was not possible to get a good statistical representation regarding measurements of the quality of the permeate in the experiments performed, due to the longer time (several hours) that it takes to obtain an acceptable stable value of the permeate conductivity when the flux is lower (see [39]). Thus, the SRF values are given for maximum concentration of $2.4 \mathrm{M}$ in the AS7 module and $1.8 \mathrm{M}$ in the AS26 module. For $0.6 \mathrm{M}$ the permeate quality results were similar in both modules (SRF around $99.0 \%$ when working in V-AGMD, and higher than $99.6 \%$ in AGMD). However, as feed concentration increased, the permeate quality decreased, especially in the V-AGMD operation, and more for the AS26 than for the AS7 module. In any case, the SRF values obtained in the treatment of feed sources with salt concentration similar to seawater were higher than $99.6 \%$, better than those typically obtained with reverse osmosis [41]. Results indicate that vacuum increased the passing of feed through the membrane pores. Taking into account the salinity of the feed, the minimum SRF values obtained in VAGMD operation with the AS7 and the AS26 modules for seawater correspond to a leak of the volumetric feed flow rate to the permeate side (membrane leak ratio) of about $0.06 \%$ and $0.12 \%$, respectively. Normalizing to the membrane surface area, these values result in $0.008 \%$ and $0.005 \%$ of the feed flow leaking through the pores to the gap per $\mathrm{m}^{2}$ of membrane surface area. The differences between these two values suggest that either the membrane leak increased with the permeate flux or that there were slight differences in the membrane sheets used in both modules (in principle, of similar characteristics). However, this is something that must be explained at membrane level, therefore requiring further laboratory analysis with access to the membrane, which cannot be done in this study with commercial modules.

\subsection{Discussion}

Previous studies of spiral-wound modules with internal heat recovery have pointed out that the longer the residence time of the feed is (directly affected by the length of the channels), the higher the thermal efficiency of the module is, because of the more intensive feed preheating (see e.g. [33]). The larger preheating of the feed, however, decreases the temperature difference between both sides of the membrane. As a result, the driving force of the process is reduced and thus less permeate is produced. This trade-off between permeate productivity and thermal efficiency remained with the vacuum enhancement: lower permeate fluxes were associated to lower values of STEC, and hence higher thermal efficiency of the MD system. However, the effect of the extraction of air from the gap needs to be seen in more detail.

Since the real transmembrane temperature difference cannot be measured in pilot-scale modules, bulk temperature measurements in both channels and in the gap were used for calculating a logarithmic mean temperature difference across the module $\left(\Delta \mathrm{T}_{\mathrm{ml}}\right)$. Comparing Fig. 7a and $\mathrm{b}$, higher values of $\Delta \mathrm{T}_{\mathrm{ml}}$ were observed in the AS7 module than in the AS26 module, confirming the previous statement on the effect of the length of the channels and the residence time. Interestingly, values of $\Delta \mathrm{T}_{\mathrm{ml}}$ were lower with the application of vacuum

Table 1

Results of SRF, membrane leak ratio and normalized membrane leak ratio in comparative experiments performed in AGMD and V-AGMD modes, using the AS7 and the AS26 module for different feed salinities. TEI $=80^{\circ} \mathrm{C}$, TCI $=25^{\circ} \mathrm{C}$, FFR $=1100 \mathrm{~h} \mathrm{~h}^{-1}$.

\begin{tabular}{|c|c|c|c|c|}
\hline FeedC $[\mathrm{M}]$ & Module and mode & SRF [\%] & Membrane leak ratio [\%] & Normalized membrane leak ratio $\left[\% \mathrm{~m}^{-2}\right]$ \\
\hline \multirow[t]{4}{*}{0.6} & AS7 AGMD & 99.89 & 0.0150 & 0.0021 \\
\hline & AS7 V-AGMD & 98.96 & 0.0438 & 0.0061 \\
\hline & AS26 AGMD & 99.69 & 0.0039 & 0.0002 \\
\hline & AS26 V-AGMD & 98.55 & 0.0372 & 0.0015 \\
\hline \multirow[t]{4}{*}{1.2} & AS7 AGMD & 99.39 & 0.0144 & 0.0020 \\
\hline & AS7 V-AGMD & 98.76 & 0.0431 & 0.0060 \\
\hline & AS26 AGMD & 99.10 & 0.0048 & 0.0002 \\
\hline & AS26 V-AGMD & 97.96 & 0.0779 & 0.0032 \\
\hline \multirow[t]{4}{*}{1.8} & AS7 AGMD & 99.30 & 0.0238 & 0.0033 \\
\hline & AS7 V-AGMD & 98.01 & 0.0556 & 0.0077 \\
\hline & AS26 AGMD & 99.03 & 0.0055 & 0.0002 \\
\hline & AS26 V-AGMD & 96.44 & 0.1225 & 0.0051 \\
\hline \multirow[t]{4}{*}{2.4} & AS7 AGMD & 99.16 & 0.0135 & 0.0019 \\
\hline & AS7 V-AGMD & 97.92 & 0.0576 & 0.0080 \\
\hline & AS26 AGMD & N/A & N/A & N/A \\
\hline & AS26 V-AGMD & N/A & N/A & $\mathrm{N} / \mathrm{A}$ \\
\hline
\end{tabular}




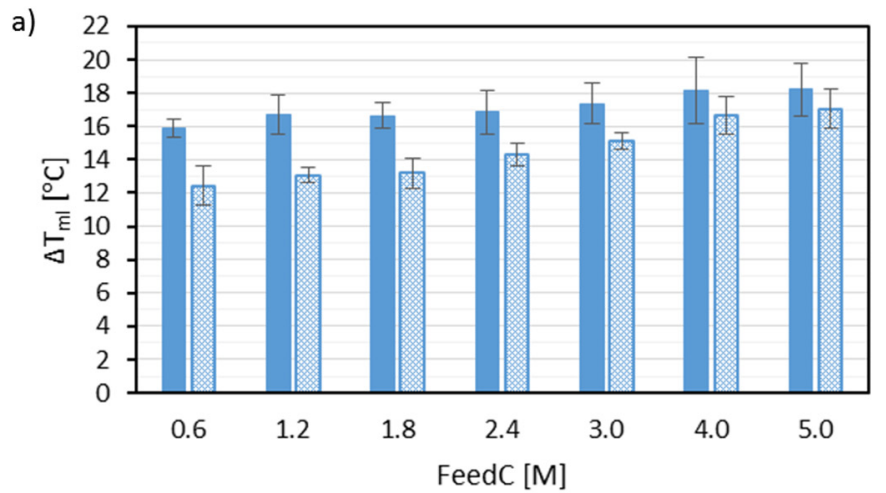

aGMD, AS7 $\quad$ V-AGMD, AS7

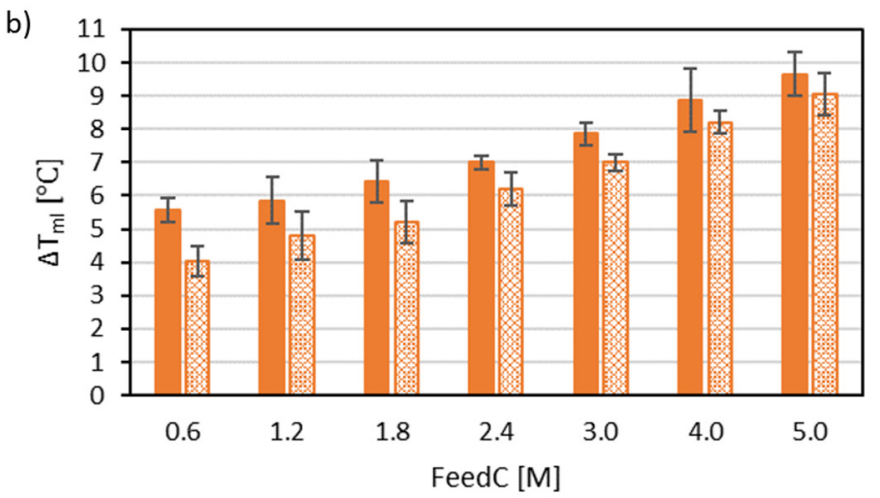

AGMD, AS26 $₫$ V-AGMD, AS26

Fig. 7. Comparative results of $\Delta \mathrm{T}_{\mathrm{ml}}$ in experiments performed in AGMD (filled columns) and V-AGMD (striped columns) using the AS7 (a) and the AS26 module (b), respectively, with different feed salinities. TEI $=80^{\circ} \mathrm{C}$, $\mathrm{TCI}=25^{\circ} \mathrm{C}, \mathrm{FFR}=1100 \mathrm{lh}^{-1}$. Error bars are shown.

(striped columns) than without it (filled columns). This is due to the larger preheating of the feed because of the larger quantity of vapour condensing in the V-AGMD mode. This also explains the increase of $\Delta \mathrm{T}_{\mathrm{ml}}$ with salinity in both cases, especially in the AS26 module, which is an effect of the stronger influence of salinity in the larger module and the fact that for comparable operating conditions, the decrease of production associated to the presence of air in the gap decreases the preheating of the feed, resulting in larger $\Delta \mathrm{T}_{\mathrm{ml}}$.

The real driving force of the process can be more closely approximated by calculating the difference of saturation vapour pressure between the evaporator side of the membrane and the gap side $(\Delta \mathrm{Pv})$, considering the logarithmic mean (Fig. 8). This vapour pressure difference reflected again the influence of the channels' length: it was smaller for the AS26 module than for the AS7 module. The behaviour of $\Delta \mathrm{Pv}$ with increasing salinity was more aligned to that of the permeate flux: it was reduced in both modules when operating without vacuum and when the feed salinity increased (filled columns in Fig. 8). However, vacuum enhancement caused different evolution of $\Delta \mathrm{Pv}$ with increasing salinity in both modules (striped columns in Fig. 8). In the AS7 module, it was almost constant ( $83 \pm 5$ mbar) for feed salinities lower than $5.0 \mathrm{M}$; at this extreme concentration it was reduced to $73 \mathrm{mbar}$. In the AS26 module, it was also stable ( $26 \pm 3$ mbar) when operating with salinity up to $3.0 \mathrm{M}$, and decreased above that.

The fact that larger permeate productivities were reached in VAGMD mode despite having lower driving force highlights the main effects of the application of vacuum: a higher mass transfer in the gap due to the enhanced diffusion by eliminating internal air. This

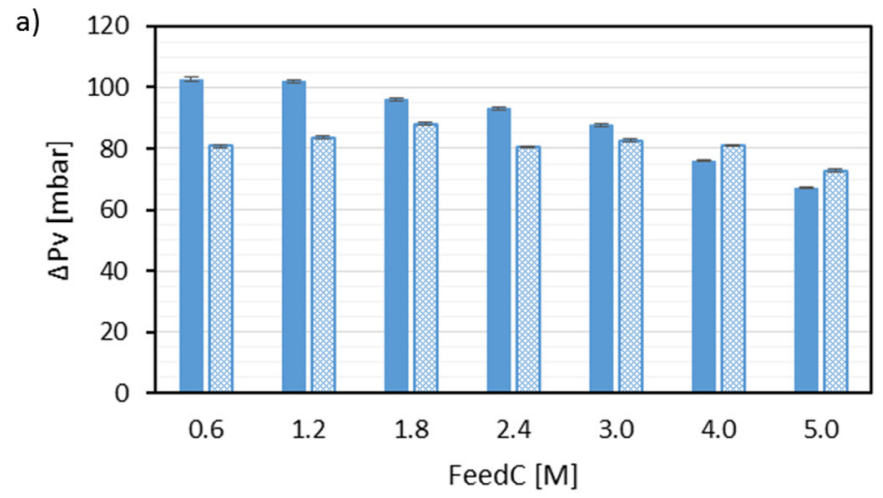

AGMD, AS7 $⿴ 囗 \mathrm{~V}-\mathrm{AGMD}, \mathrm{AS7}$

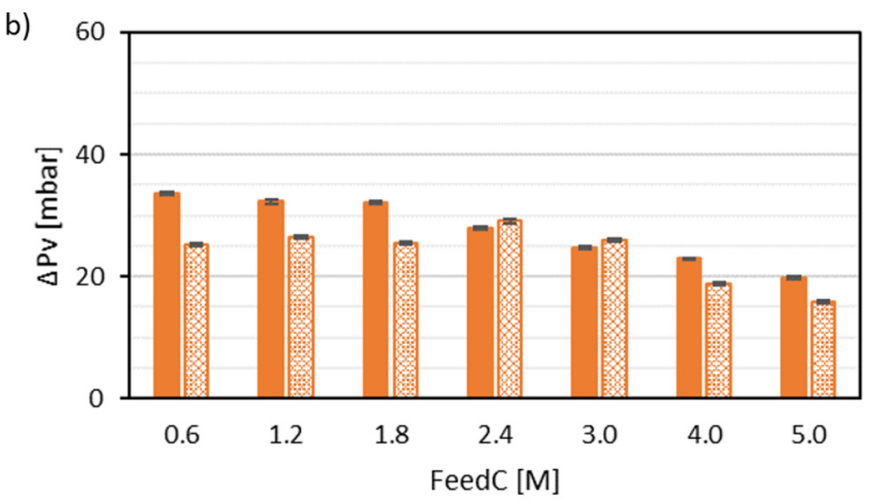

$\square$ AGMD, AS26 잠 V-AGMD, AS26

Fig. 8. Comparative results of $\Delta \mathrm{PV}$ in experiments performed in AGMD (filled columns) and V-AGMD (striped columns) using the AS7 (a) and the AS26 module (b), respectively, with different feed salinities. TEI $=80^{\circ} \mathrm{C}$, $\mathrm{TCI}=25^{\circ} \mathrm{C}$, FFR $=1100 \mathrm{lh}^{-1}$. Error bars are shown.

increased production decreases the temperature difference between both sides of the membrane (Fig. 7), and hence reduces the driving force (Fig. 8). Since the permeate flux was larger in spite of this, the dominant role of reducing the mass transfer resistance is underlined.

The previous results demonstrate the beneficial effect of the vacuum for increasing the permeate productivity and reducing the thermal energy consumption. One of the main innovations in the commercial system analysed is the use of a cost-effective solution based on the Venturi effect for sucking air from the gap without using a vacuum pump, but the cooling circuit pump itself, reducing in this way the specific electric consumption (SEC) down to values below $200 \mathrm{Wh}_{\mathrm{el}}$ $\mathrm{m}^{-3}, 25$-fold lower than other commercial vacuum-based MD systems [42].

To highlight the importance of the results obtained in the present study, a comparative representation of permeate flux versus GOR as suggested by Winter et al. [43] was used. Results for feed salinity around $0.6 \mathrm{M}$ and evaporator and cooling channels inlet temperatures of 80 and $25^{\circ} \mathrm{C}$, respectively, were compiled and compared in Fig. 9 (see Table 2 for labels identification), considering only pilot-scale experiments with spiral-wound single-effect modules. Also included in this figure are results from Winter's thesis in AGMD (\#9) and V-AGMD (\#10) for a single envelope spiral-wound module [37]. The energy efficiency obtained with Winter's module in V-AGMD was better than that obtained with the AS7 in this work. This can be explained observing that the residence time in Winter's module $(83.3 \mathrm{~s}$ ) was larger than in the AS7 module (from 18.5 to $51.7 \mathrm{~s}$ ). The AS26 module is more adequate for the comparison, considering the residence times from 66.6 to 


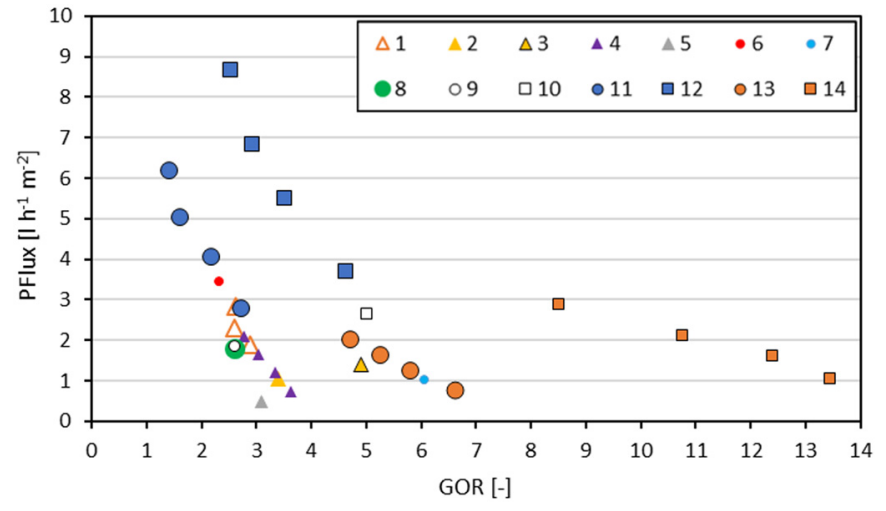

Fig. 9. Comparison of AGMD (circles), V-AGMD (squares) and PGMD (triangles) results from different pilot-scale studies with spiral-wound modules reported in the literature $\left(\mathrm{TEI}=80^{\circ} \mathrm{C}, \mathrm{TCI}=25^{\circ} \mathrm{C}\right.$, FeedC $\left.=0.6 \mathrm{M}\right)$. Series numbered in the figure are detailed in Table 2.

$183.2 \mathrm{~s}$. It is remarkable that the worst energy efficiency achieved with the AS26 in this work (GOR $=8.5$ ) is still better than that of Winter's module in V-AGMD (GOR $=5$ ). Moreover, the permeate flux obtained with Winter's module was only slightly lower than that obtained with the AS26 module for the worst case, which corresponds to the largest feed velocity, which was still half that of Winter's. The better performance of the spiral wound modules used in this study could be related to the narrower gap $(0.76 \mathrm{~mm}$ vs. $2 \mathrm{~mm}$ in [37]) and the fact that the membranes have no backing (Winter's module used PTFE membranes with active layer of $70 \mu \mathrm{m}$ and PP backing of $280 \mu \mathrm{m}$ ), which benefits the permeate flux.

Also shown in Fig. 9 are results of Schwantes et al. [44], who proposed an alternative AGMD strategy for high salinity feed treatment based on sparging a constant low air flow inside the gap (resulting in maximum 40 mbar above atmospheric pressure). This was demonstrated as an efficient way of draining the gap and avoiding water contact between the feed channel and the gap through the membrane pores, thus reducing membrane wetting. However, the increased mass transfer resistance in the gap due to the additional air could reduce the performance compared to standard AGMD and V-AGMD. It is yet to be seen whether the latter helps also avoiding water bridges, something not possible to check in a pilot-scale module. Previous results for seawater desalination with AS7 and AS26 modules in AGMD configuration (\#6 and \#7 respectively) [25] are plotted in Fig. 9, as well as results of PGMD for SolarSpring modules in different conditions (\#1 - \#5), with generally worse performance than AGMD. It is interesting to compare
\#3 to \#2, however, in order to observe the increase of performance by deaerating the feed. The performance increase of the vacuum-enhanced operation in AGMD is much larger (comparing \#14 to \#13 and \#12 to \#11).

Fig. 9 only shows a benchmarking of the results obtained in our work against other spiral wound single-effect MD modules reported in the literature. A completely different concept based on multi-effect plate and frame modules under vacuum (V-MEMD) was proposed by memsys in 2010 [45]. They achieved high internal latent heat recovery [46]. Results obtained in this study with the AS7 module and vacuum enhancement (\#12) were close to those previously reported for a 4effect V-MEMD operating under similar operating conditions: PFlux up to $8.51 \mathrm{~h}^{-1} \mathrm{~m}^{-2}$ and GOR up to 3.3 [42]. The AS26 module in V-AGMD operation (\#14) yielded 3-fold lower PFlux but with 4 times higher thermal efficiency than the V-MEMD module. It must be stressed that the V-MEMD module was operated fully under vacuum, with pressure lower than the equilibrium (less than 100 mbar in the condenser) and using a vacuum pump with high electrical consumption.

\section{Conclusions}

The results obtained in this study suggest that membrane distillation using multi-envelope spiral-wound modules in V-AGMD operation is currently the best available technology for the desalination of highconcentrated solutions. The spiral-wound modules evaluated in this study in V-AGMD configuration demonstrated excellent performance in a wide range of feed salinities. The strong increase of the vapour transfer through the pores caused by the removal of air from the gap, resulted in a drastic improvement of the performance in relation to normal AGMD operation. In accordance with the well-known trade-off between permeate flux and thermal efficiency and its relation to the channel length, the maximum permeate productivity $\left(8.71 \mathrm{~h}^{-1} \mathrm{~m}^{-2}\right)$ was yielded by the shortest module (AS7, with $1.5 \mathrm{~m}$ channel length) with the shortest residence time, and the maximum heat efficiency $\left(49 \mathrm{kWh}_{\mathrm{th}} \mathrm{m}^{-3}\right.$, or GOR $\left.=13.5\right)$ was measured with the longest module (AS26, with $2.7 \mathrm{~m}$ channel length) with the longest residence time.

The enhancement of permeate productivity (about half more flux) and energy efficiency (about half less specific thermal energy consumption) due to the use of vacuum in the gap were achieved almost independently of the feed salinity in the assessed range ( 0.6 to $5 \mathrm{M})$ for the AS7 module, and improved with the salinity of the feed for the AS26 module, especially above $3 \mathrm{M}$. This is an important result for the treatment of high salinity sources with thermal separation technologies. Operation in V-AGMD allowed extending the use of the AS26 module, which is the most thermally efficient one, to feeds of $5 \mathrm{M}$ concentration, which was not possible in AGMD operation with this module. This

Table 2

Detailed information about the series shown in Fig. 9.

\begin{tabular}{|c|c|c|c|c|c|c|c|c|c|}
\hline Series \# & Operational mode & Membrane area $\left[\mathrm{m}^{2}\right]$ & \# of spiral envelopes & Channel length [m] & FFR $\left[l h^{-1}\right]$ & Feed velocity $\left[\mathrm{cm} \mathrm{s}^{-1}\right]$ & $\begin{array}{l}\text { PFlux } \\
{\left[1 \mathrm{~h}^{-1} \mathrm{~m}^{-2}\right]}\end{array}$ & GOR $[-]$ & Reference \\
\hline 1 & PGMD & 10 & 1 & 7 & $400-600$ & $6.2-9.3$ & $1.9-2.8$ & $2.9-2.6$ & [18] \\
\hline 2 & PGMD & 10 & 1 & 7 & 300 & 7.4 & 1.1 & 3.4 & [33] \\
\hline 3 & PGMD $^{\mathrm{a}}$ & 10 & 1 & 7 & 300 & 7.4 & 1.4 & 4.9 & [33] \\
\hline 4 & PGMD & 10 & 1 & 7 & $200-500$ & $3.1-7.8$ & $0.8-2.1$ & $3.6-2.8$ & [15] \\
\hline 5 & PGMD & 10 & 1 & 7 & 300 & 4.7 & 0.5 & 3.1 & [16] \\
\hline 6 & AGMD & 7.2 & 6 & 1.5 & 500 & 3.7 & 3.4 & 2.3 & {$[25]$} \\
\hline 7 & AGMD & 24 & 6 & 5 & 500 & 3.7 & 1.0 & 6.1 & [25] \\
\hline 8 & $\mathrm{AGMD}^{\mathrm{b}}$ & 8.3 & 1 & 6 & 300 & 7.5 & 1.8 & 2.6 & [44] \\
\hline 9 & AGMD & 8.7 & 1 & 6.5 & 300 & 7.8 & 1.8 & 2.6 & [37] \\
\hline 10 & V-AGMD & 8.7 & 1 & 6.5 & 300 & 7.8 & 2.6 & 5.0 & {$[37]$} \\
\hline 11 & AGMD & 7.2 & 6 & 1.5 & $400-1100$ & $2.9-8.1$ & $2.8-6.2$ & $2.7-1.4$ & This study \\
\hline 12 & V-AGMD & 7.2 & 6 & 1.5 & $400-1100$ & $2.9-8.1$ & $3.7-8.7$ & $4.6-2.5$ & This study \\
\hline 13 & AGMD & 25.9 & 12 & 2.7 & $400-1100$ & $1.5-4.1$ & $0.8-2.0$ & $6.6-4.7$ & This study \\
\hline 14 & V-AGMD & 25.9 & 12 & 2.7 & $400-1100$ & $1.5-4.1$ & $1.1-2.9$ & $13.5-8.5$ & This study \\
\hline
\end{tabular}

\footnotetext{
a Deaerated module.

b With overpressure in the gap.
} 
means that very high salinity sources can be treated with STEC lower than $515 \mathrm{kWh} \mathrm{m}^{-3}$ (equivalent to GOR $=1.2$ ).

Considering that extraction of the air from the gap was achieved with a Venturi effect using a circulating pump, and therefore with minimum additional electric energy consumption, the main drawback of V-AGMD was the permeate quality. Results of salt rejection factor in the whole range of salinities studied suggest that vacuum increased the passing of feed through the membrane pores. Although these leaks add up to less than $0.5 \%$ of the volumetric feed flow rate, pore wetting could be boosted and perhaps the formation of seed crystals inside the pores. This must be further examined, in laboratory analysis where access to the membrane (for measurements and imaging) can be possible.

Finally, the permeate fluxes measured for seawater desalination with the AS7 module in V-AGMD operation in this work were generally larger than all the others measured with other single-effect MD modules in comparable conditions. In addition, the GOR values obtained with the AS26 module were also much larger than others reported so far. Indeed, the maximum GOR achieved for seawater desalination with the AS26 module in V-AGMD operation was more than twice the largest value obtained so far with MD modules reported in the literature. This is a record thermal efficiency for MD and is comparable to the best results obtained with industrial-scale thermal desalination technologies like MSF or MED [47].

\section{Nomenclature}

Symbols

\begin{tabular}{|c|c|}
\hline A & $\mathrm{m}^{2}$, Membrane area \\
\hline $\mathrm{Cp}_{\mathrm{f}}$ & 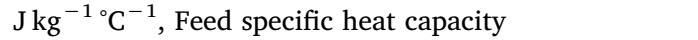 \\
\hline FeedC & moll $1^{-1}$, Feed concentration \\
\hline FFR & $1 \mathrm{~h}^{-1}$, Feed flow rate \\
\hline GOR & -, Gained output ratio \\
\hline M & mol $1^{-1}$, Molarity \\
\hline $\mathrm{P}$ & mbar, Pressure \\
\hline PermC & moll $1^{-1}$, Permeate concentration \\
\hline PFlux & $1 \mathrm{~h}^{-1} \mathrm{~m}^{-2}$, Permeate flux \\
\hline Psat $_{C}$ & mbar, Saturation pressure into the cooling channels \\
\hline Psat $_{\mathrm{E}}$ & mbar, Saturation pressure into the evaporator channels \\
\hline SEC & $\mathrm{kWh}_{\mathrm{el}} \mathrm{m}^{-3}$, Specific electric consumption \\
\hline SRF & $\%$, Salt rejection factor \\
\hline STEC & $\mathrm{kWh}_{\mathrm{th}} \mathrm{m}^{-3}$, Specific thermal energy consumption \\
\hline $\mathrm{T}$ & ${ }^{\circ} \mathrm{C}$, Temperature \\
\hline TCI & ${ }^{\circ} \mathrm{C}$, Cooling channel inlet temperature \\
\hline TCO & ${ }^{\circ} \mathrm{C}$, Cooling channel outlet temperature \\
\hline TEI & ${ }^{\circ} \mathrm{C}$, Evaporation channel inlet temperature \\
\hline TEO & ${ }^{\circ} \mathrm{C}$, Evaporation channel outlet temperature \\
\hline$\Delta \mathrm{H}_{\mathrm{v}}$ & $\mathrm{J} \mathrm{kg}^{-1}$, Latent heat of vaporization \\
\hline$\Delta \mathrm{P}_{\mathrm{v}}$ & mbar, Logarithmic mean vapour pressure difference \\
\hline$\Delta \mathrm{T}_{\mathrm{ml}}$ & ${ }^{\circ} \mathrm{C}$, Logarithmic mean temperature difference \\
\hline$\eta$ & $\%$, Thermal efficiency of the membrane \\
\hline$\rho_{\mathrm{f}}$ & $\mathrm{kg} \mathrm{m}^{-3}$, Feed density \\
\hline & $\mathrm{kg} \mathrm{m}^{-3}$, Permeate density \\
\hline
\end{tabular}

Abbreviations

AGMD air-gap membrane distillation

AS26 module AS26C2.7L

AS7 module AS7C1.5L

DCMD direct-contact membrane distillation

LDPE low-density polyethylene

MD membrane distillation

MED Multi-effect distillation

MSF Multi-stage flash evaporation

PET Polyethylene terephthalate
PGMD permeate-gap membrane distillation

PLC programmable logic controller

RO reverse osmosis

V-AGMD vacuum-enhanced air gap membrane distillation

VMD vacuum membrane distillation

\section{Subscripts}

C Cooling

E Evaporation

f Feed

$\mathrm{ml} \quad$ Logarithmic mean

p Permeate

v Vapour

\section{Acknowledgements}

This work was performed within the RED-Heat-to-Power project (Conversion of Low Grade Heat to Power through closed loop Reverse Electro-Dialysis), funded by EU within the Horizon 2020 research \& innovation programme, grant agreement No: 640667. www.red-heatto-power.eu.

\section{References}

[1] M. Khayet, Solar desalination by membrane distillation: dispersion in energy consumption analysis and water production costs (a review), Desalination 308 (2013) 89-101.

[2] Y. Zhang, Y. Peng, S. Ji, Z. Li, P. Chen, Review of thermal efficiency and heat recycling in membrane distillation processes, Desalination 367 (2015) 223-239.

[3] G. Zaragoza, J.A. Andrés-Mañas, A. Ruiz-Aguirre, Commercial scale membrane distillation for solar desalination, npj Clean Water 1 (2018) 20.

[4] E. Drioli, A. Ali, F. Macedonio, Membrane operations for process intensification in desalination, Appl. Sci. 7 (2017) 100.

[5] D. González, J. Amigo, F. Suárez, Membrane distillation: perspectives for sustainable and improved desalination, Renew. Sust. Energ. Rev. 80 (2017) 238-259.

[6] N. Thomas, M.O. Mavukkandy, S. Loutatidou, H.A. Arafat, Membrane distillation research \& implementation: lessons from the past five decades, Sep. Purif. Technol. 189 (2017) 108-127.

[7] G.Q. Guan, X. Yang, R. Wang, A.G. Fane, Evaluation of heat utilization in membrane distillation desalination system integrated with heat recovery, Desalination 366 (2015) 80-93.

[8] G. Dong, J.F. Kim, J.H. Kim, E. Drioli, Y.M. Lee, Open-source predictive simulators for scale-up of direct contact membrane distillation modules for seawater desalination, Desalination 402 (2017) 72-87.

[9] E.K. Summers, H.A. Arafat, J.H. Lienhard V, Energy efficiency comparison of singlestage membrane distillation (MD) desalination cycles in different configurations, Desalination 290 (2012) 54-66.

[10] H.W. Chung, J. Swaminathan, D.M. Warsinger, J.H. Lienhard V, Multistage vacuum membrane distillation (MSVMD) systems for high salinity applications, J Memb Sci 497 (2016) 128-141.

[11] H. Geng, J. Wang, C. Zhang, P. Li, H. Chang, High water recovery of RO brine using multi-stage air gap membrane distillation, Desalination 355 (2015) 178-185.

[12] E. Guillén-Burrieza, J. Blanco, G. Zaragoza, D.C. Alarcón-Padilla, P. Palenzuela, M. Ibarra, et al., Experimental analysis of an air gap membrane distillation solar desalination pilot system, J Memb Sci 379 (2011) 386-396.

[13] E. Guillén-Burrieza, G. Zaragoza, S. Miralles-Cuevas, J. Blanco, Experimental evaluation of two pilot-scale membrane distillation modules used for solar desalination, J Memb Sci 409-410 (2012) 264-275.

[14] A. Kullab, A. Martin, Membrane distillation and applications for water purification in thermal cogeneration plants, Sep. Purif. Technol. 76 (2011) 231-237.

[15] D. Winter, J. Koschikowski, M. Wieghaus, Desalination using membrane distillation: experimental studies on full scale spiral wound modules, J Memb Sci 375 (2011) 104-112.

[16] R. Schwantes, A. Cipollina, F. Gross, J. Koschikowski, D. Pfeifle, M. Rolletschek, et al., Membrane distillation: solar and waste heat driven demonstration plants for desalination, Desalination 323 (2013) 93-106.

[17] F. Banat, N. Jwaied, M. Rommel, J. Koschikowski, M. Wieghaus, Performance evaluation of the "large SMADES" autonomous desalination solar-driven membrane distillation plant in Aqaba, Jordan, Desalination 217 (2007) 17-28.

[18] A. Ruiz-Aguirre, J.A. Andrés-Mañas, J.M. Fernández-Sevilla, G. Zaragoza, Modeling and optimization of a commercial permeate gap spiral wound membrane distillation module for seawater desalination, Desalination 419 (2017) 160-168.

[19] A. Ruiz-Aguirre, D.C. Alarcón-Padilla, G. Zaragoza, Productivity analysis of two spiral-wound membrane distillation prototypes coupled with solar energy, Desalin. Water Treat. 55 (2015) 2777-2785.

[20] A. Ruiz-Aguirre, J.A. Andrés-Mañas, J.M. Fernández-Sevilla, G. Zaragoza, Comparative characterization of three commercial spiral-wound membrane 
distillation modules, Desalin. Water Treat. 61 (2017) 152-159.

[21] H.C. Duong, A.R. Chivas, B. Nelemans, M. Duke, S. Gray, T.Y. Cath, et al. Treatment of RO brine from CSG produced water by spiral-wound air gap membrane distillation - a pilot study, Desalination 366 (2015) 121-129.

[22] I. Hitsov, K. De Sitter, C. Dotremont, P. Cauwenberg, I. Nopens, Full-scale validated Air Gap Membrane Distillation (AGMD) model without calibration parameters, J Memb Sci 533 (2017) 309-320.

[23] H.C. Duong, P. Cooper, B. Nelemans, T.Y. Cath, L.D. Nghiem, Evaluating energy consumption of air gap membrane distillation for seawater desalination at pilot scale level, Sep. Purif. Technol. 166 (2016) 55-62.

[24] G. Zaragoza, A. Ruiz-Aguirre, E. Guillén-Burrieza, Efficiency in the use of solar thermal energy of small membrane desalination systems for decentralized water production, Appl. Energy 130 (2014) 491-499.

[25] A. Ruiz-Aguirre, J.A. Andrés-Mañas, J.M. Fernández-Sevilla, G. Zaragoza, Experimental characterization and optimization of multi-channel spiral wound air gap membrane distillation modules for seawater desalination, Sep. Purif. Technol. 205 (2018) 212-222.

[26] C.M. Guijt, G.W. Meindersma, T. Reith, A.B. De Haan, Air gap membrane distillation 2: model validation and hollow fibre module performance analysis, Sep. Purif. Technol. 43 (2005) 245-255.

[27] Q. He, P. Li, H. Geng, G. Zhang, J. Wang, H. Chang, Modeling and optimization of air gap membrane distillation system for desalination, Desalination 354 (2014) 68-75.

[28] K. Yao, Y.J. Qin, Y.J. Yuan, L.Q. Liu, F. He, Y. Wu, A continuous-effect membrane distillation process based on hollow fibre AGMD module with internal latent-heat recovery, AICHE J. 59 (2012) 1278-1297.

[29] H. Geng, Q. He, H. Wu, P. Li, C. Zhang, H. Chang, Experimental study of hollow fibre AGMD modules with energy recovery for high saline water desalination, Desalination 334 (2014) 55-63.

[30] M. Khayet, Membranes and theoretical modeling of membrane distillation: a review, Adv. Colloid Interf. Sci. 164 (2011) 56-88.

[31] G. Rao, S.R. Hiibel, A. Achilli, A.E. Childress, Factors contributing to flux improvement in vacuum-enhanced direct contact membrane distillation, Desalination 367 (2015) 197-205.

[32] G. Naidu, S. Jeong, S. Vigneswaran, Influence of feed/permeate velocity on scaling development in a direct contact membrane distillation, Sep. Purif. Technol. 125 (2014) 291-300.

[33] D. Winter, J. Koschikowski, S. Ripperger, Desalination using membrane distillation: flux enhancement by feed water deaeration on spiral-wound modules, J Memb Sci
423-424 (2012) 215-224.

[34] A.S. Alsaadi, L. Francis, H. Maab, G.L. Amy, N. Ghaffour, Evaluation of air gap membrane distillation process running under sub-atmospheric conditions: experimental and simulation studies, J Memb Sci 489 (2015) 73-80.

[35] M.A.E.R. Abu-Zeid, L. Zhang, W.Y. Jin, T. Feng, Y. Wu, H.L. Chen, et al., Improving the performance of the air gap membrane distillation process by using a supplementary vacuum pump, Desalination 384 (2016) 31-42.

[36] Z. Liu, Q. Gao, X. Lu, Z. Ma, H. Zhang, C. Wu, Experimental study of the optimal vacuum pressure in vacuum assisted air gap membrane distillation process, Desalination 414 (2017) 63-72.

[37] D. Winter, Membrane Distillation: A Thermodynamic, Technological and Economic Analysis, Ph.D. Thesis (2014).

[38] M.H. Sharqawy, J.H. Lienhard V, S.M. Zubair, Thermophysical properties of seawater: a review of existing correlations and data, Desalin. Water Treat. 16 (2010) 354-380.

[39] A. Ruiz-Aguirre, J.A. Andrés-Mañas, G. Zaragoza, Evaluation of permeate quality in pilot scale membrane distillation systems, Membranes 9 (6) (2019) 69.

[40] J.H. Lienhard V, M. Antar, A. Bilton, J. Blanco, G. Zaragoza, Annual review of heat transfer, Solar Desalin 15 (2012) 277-347.

[41] R. García-Pacheco, J. Landaburu-Aguirre, P. Terrero-Rodríguez, E. Campos, F. Molina-Serrano, et al., Validation of recycled membranes for treating brackish water at pilot scale, Desalination 433 (2018) 199-208.

[42] J.A. Andrés-Mañas, A. Ruiz-Aguirre, F.G. Acién, G. Zaragoza, Assessment of a pilot system for seawater desalination based on vacuum multi-effect membrane distillation with enhanced heat recovery, Desalination 443 (2018) 110-121.

[43] D. Winter, J. Koschikowski, F. Gross, D. Maucher, D. Düver, et al., Comparative analysis of full-scale membrane distillation contactors: methods and modules, J Memb Sci 524 (2017) 758-771.

[44] R. Schwantes, L. Bauer, K. Chavan, D. Dücker, C. Felsmann, J. Pfafferott, Air gap membrane distillation for hypersaline brine concentration: operational analysis of a full-scale module. New strategies for wetting mitigation, Desalination 444 (2018) $13-25$.

[45] W. Heinzl, S. Heinzl, S. Büttner, G. Lange, Industrialized modules for MED desalination with polymer surfaces, Desalin. Water Treat. 42 (2012) 177-180.

[46] K. Zhao, W. Heinzl, M. Wenzel, S. Büttner, F. Bollen, G. Lange, et al., Experimental study of the memsys vacuum multi-effect membrane distillation (V-MEMD) module, Desalination 323 (2013) 150-160.

[47] M.W. Shahzad, M. Burhan, L. Ang, K.C. Ng, Energy-water-environment nexus underpinning future desalination sustainability, Desalination 413 (2017) 52-64. 